\title{
Complexity, Interdisciplinarity, and the Real World: Meaningful Collaboration in a Seminar Setting
}

\author{
TRACI ROSE RIDER \\ North Carolina State University
}

The architecture profession is shifting in scope, engagement, responsibility, and processes. The traditional journey of professional preparation for architects is proven and established, but does not readily adapt to the dynamic contexts of the profession. Real-world problems are largely simulated through in-person studio and professional practice courses, which often foster the disconnection of the architecture student, both from other disciplines as well as from real-world application. To align with the changing context of the profession, the standard curriculum is being asked to incorporate issues such as tactile experimentation and entrepreneurship. Programs are also asked to address expanded knowledge around standard issues like energy consumption and stormwater, as well as those previously seen on the periphery, such as food production and human health. This paper highlights two seminar courses that speak to three critically important issues for future practitioners: (1) growing knowledge in important topics cutting across building types, specifically building operations and health; (2) meaningful collaborative, interdisciplinary team work; and (3) engagement with real-world projects, practicing professionals, and clients. This paper presents course objectives, course structure, real-world collaboration methods, and feedback from students in architecture and other engaged disciplines. Specific attention will be given to team building exercises and differing disciplinary approaches to the problem topics, sharing results from different student assessment methods. Additional opportunities for future research are identified.

\section{BACKGROUND}

While themes of health and sustainability are increasingly popular in architectural education, mirroring the increased interest in professional practice, these issues are often being force-fit into traditional content delivery systems. Specifically, relevant issues such as energy modeling, site systems, operations and maintenance, and health are being addressed within a commonly insular approach to design education, likely in studio setting or a seminar course largely comprised of architecture majors. However, with the complexity inherent in these challenging topics addressing both environmental and human health, particularly in architecture, interdisciplinary teamwork is required; architects alone cannot tackle these wicked problems. With increased attention to integrated processes within allied professions, both future and practicing architects are progressively asked to establish modified dialogues and methods to better collaborate with these disciplines (Yudelson 2008, Reed 2011, Keeler and Vaidya 2016).
Literature clearly illustrates that higher education courses embracing interdisciplinary teamwork better prepare students for future real-world projects (Fixson 2009, Smit and Tremethick 2013). However, the core of the architectural curriculum - the studio - does not easily afford interdisciplinary engagement, given differing credit hour structures, time required, and disciplinary understandings of processes in design and construction. Though studios integrated with other disciplines are happening, they are not widespread (Rider 2010). Established courses where architecture students might see other disciplines, such as large lectures, also do not have a structure that readily encourages meaningful interdisciplinary interaction and engagement. Those courses where meaningful conversations and teamwork could be fostered, such as studio, are not as welcoming for the other fields. Courses that welcome other disciplines into balanced, meaningful conversations are few, and not readily documented (Rider and Bowen 2016).

As a response to the gap in these opportunities, this paper reviews two interdisciplinary courses addressing sustainability and health through a case study comparison. The case study methodology maintains that context is integral to the findings of the study (Yin 2009), and cannot necessarily be generalized to other settings or populations. However, knowledge may be transferrable. Both courses consist of students from architecture, civil engineering, and environmental sciences, and focus on sustainability and health themes. The courses are similarly structured, and both engage real-world projects as a method to provide meaningful interdisciplinary engagement.

\section{COURSE OBJECTIVES}

The two courses reviewed are the LEED Lab course hosted in the fall, and the Toward Sustainability course hosted in the spring. course objectives for the two courses are similar, focusing on different topic areas. The stated goals and objectives for the two courses are compared below in Table 1. As shown, the overarching goals are similar in that they emphasize interdisciplinarity and established frameworks. While the fall course is very specific to the terms, thresholds and requirements of the Leadership in Energy and Environmental Design (LEED) rating system, the spring course is more broad and exploratory, using existing frameworks and rating systems as structures to guide explorations and critical thought. 


\begin{tabular}{|c|c|}
\hline LEED Lab Course (Fall) & Toward Sustainability (Spring) \\
\hline $\begin{array}{l}\text { Goal: ...this course will emphasize the importance of } \\
\text { interdisciplinary work while working toward sustainability goals. } \\
\text { Over the course of the semester, students will research various } \\
\text { criteria in-depth which are needed for LEED Existing Building } \\
\text { Certification, not only becoming familiar with the rating system } \\
\text { itself, but also the foundation for each of the addressed LEED } \\
\text { credits, as well as context for decisions made in the realm of } \\
\text { green buildings. }\end{array}$ & $\begin{array}{l}\text { Goal: The intent of this course is to understand what achieving } \\
\text { sustainability in the built environment truly means, and to } \\
\text { critically assess methods and opportunities to reach that difficult } \\
\text { goal by exploring established frameworks through an } \\
\text { interdisciplinary lens. }\end{array}$ \\
\hline Similar objectives & Similar objectives \\
\hline $\begin{array}{l}\text { Objective 1: To provide students with a solid understanding of } \\
\text { implementation issues regarding the sustainability movement in } \\
\text { the real world of the built environment. }\end{array}$ & $\begin{array}{l}\text { Objective 1: To provide students with a solid understanding of } \\
\text { design issues regarding the sustainability movement in the real } \\
\text { world of the built environment. }\end{array}$ \\
\hline $\begin{array}{l}\text { Objective 2: To give students the skills necessary to explore } \\
\text { alternative interventions for increased buildings performance } \\
\text { and propose greener opportunities. }\end{array}$ & $\begin{array}{l}\text { Objective 2: To give students the skills necessary to explore } \\
\text { alternative interventions for increased buildings performance } \\
\text { and propose greener opportunities, through a holistic lens. }\end{array}$ \\
\hline $\begin{array}{l}\text { Objective 3: To expand critical thinking and analysis skills, as } \\
\text { well as further develop research and writing abilities. }\end{array}$ & $\begin{array}{l}\text { Objective 3: To expand critical thinking and analysis skills, as } \\
\text { well as further develop research and writing abilities. }\end{array}$ \\
\hline Differing objectives & Differing objectives \\
\hline $\begin{array}{l}\text { Objective 4: To supply students with experience with actual } \\
\text { performance metrics in existing building use. }\end{array}$ & $\begin{array}{l}\text { Objective 4: To engage students in real world projects with } \\
\text { potential to implement differing aspects of long-term } \\
\text { sustainability. }\end{array}$ \\
\hline $\begin{array}{l}\text { Objective 5: To give students real world experience in upgrading } \\
\text { campus facilities for energy savings and long-term sustainability. }\end{array}$ & $\begin{array}{l}\text { Objective 5: To engage students and professionals in the design } \\
\text { process and in the green strategy development process, to } \\
\text { better understand the relationship between design strategies } \\
\text { and projected outcomes in the built environment. }\end{array}$ \\
\hline $\begin{array}{l}\text { Objective 6: To engage users of the building in the green } \\
\text { strategy development process, to better understand the } \\
\text { relationship between occupants and their built environment. }\end{array}$ & $\begin{array}{l}\text { Objective 6: To offer students the opportunity to explore in- } \\
\text { depth different green building rating systems, including those } \\
\text { that will host the next generations of considerations. }\end{array}$ \\
\hline $\begin{array}{l}\text { Objective 7: To work toward certifying a campus building under } \\
\text { the LEED for Existing Buildings rating system. }\end{array}$ & - \\
\hline $\begin{array}{l}\text { Objective 8: To offer students the opportunity to sit for the } \\
\text { LEED AP exam, which requires documented experience on a } \\
\text { LEED project. }\end{array}$ & - \\
\hline
\end{tabular}

Table 1. Course goals and objectives comparison.

The differences in the specific topics of the courses can be seen in the objectives. The first three objectives are essentially the same, addressing foundational understandings, critical thinking and analysis opportunities. Objectives 4-8 and 4-6, respectively, diverge and begin to address particularities for the topic areas. These latter objectives for the LEED Lab course speak to engaging performance metrics, building operations and maintenance standards, user engagement, building certification, and the ability to sit for the LEED AP exam. The LEED Lab objectives focus more on the operation of the building after occupancy, supporting the emphasis of the course. The objectives for the spring Toward Sustainability course are focused on engaging the real world in largely emerging issues for the built environment in terms of health. These objectives are about exploration and collaboration in seeking possible solutions to newer questions. The course objectives and goals for the two classes illustrate the similarity between the two in emphasizing real-world application and interdisciplinary teams, while also outlining the differing emphasis between post-occupancy metrics and exploratory concepts for real-world application.

\section{COURSE STRUCTURE}

The two courses profiled are each held in one three-hour session per week. They are elective seminar courses and have similar elements that provide structure, expertise, and exposure to the students, focusing on the respective topics of each course. Both courses engage students from different disciplines, though the makeup differs between the two. Common elements include team building exercises, expert guest speakers, multiple team presentations, and interaction with real world projects and practitioners.

\section{SEMESTER STRUCTURE}

Both courses have the same three-pronged scaffolding structure across the semester: (1) foundational content delivery, (2) teamwork with guest experts, and (3) realworld application. Generally, the first four weeks are dedicated to establishing a fundamental overview of the subjects and considerations, given that many of the students participating have no background in the topics and/ or frameworks being addressed in the course. For the fall 


\begin{tabular}{|c|c|c|c|c|}
\hline & & LEED Lab & Toward Sustainability & \\
\hline \multirow{4}{*}{$\stackrel{-1}{\frac{+}{2}}$} & Week 1 & Intro; Category review & Intro; LEED Overview (G) & \multirow{4}{*}{ 站 } \\
\hline & Week 2 & Category review (con't) & WELL Overview (G) & \\
\hline & Week 3 & Project tour (G) & Living Building Overview (G) & \\
\hline & Week 4 & Teamwork development & Comparing and Contrasting Systems & \\
\hline \multirow{6}{*}{$\begin{array}{l}\mathbf{N} \\
\stackrel{ \pm}{\mathbf{S}} \\
\mathbf{D}\end{array}$} & Week 5 & Module 1: University context (G) & Group work & \multirow{7}{*}{ 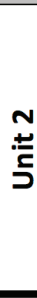 } \\
\hline & Week 6 & Module 1: Sites/LEED Boundary (G) & Student delivered content (WELL/LBC) & \\
\hline & Week 7 & FALL BREAK & Student delivered content (WELL/LBC) & \\
\hline & Week 8 & Facility tour (G) & Student delivered content (WELL/LBC) & \\
\hline & Week 9 & Module 1: Energy (G) & SPRING BREAK & \\
\hline & Week 10 & Module 1: Student Presentations & Student delivered content (Energy) (G) & \\
\hline \multirow{6}{*}{$\begin{array}{l}m \\
\stackrel{n}{c} \\
5 \\
\end{array}$} & Week 11 & Module 2: Group work & Assessment of Criteria & \\
\hline & Week 12 & Module 2: Indoor environments (G) & Firm meeting \#1 & \multirow{5}{*}{$\begin{array}{l}m \\
\stackrel{m}{c} \\
\frac{ \pm}{5}\end{array}$} \\
\hline & Week 13 & Module 2: Waste audit & Workshop \#1 & \\
\hline & Week 14 & THANKSGIVING BREAK & Firm Meeting \#2 & \\
\hline & Week 15 & Module 2: Student Presentations & Workshop \#2 & \\
\hline & Week 16 & Owner Charrette & Presentations to partners/ clients & \\
\hline
\end{tabular}

Table 2. Course structure comparison. $(G)$ indicates guest speaker.

course, these weeks consist of an overview of the LEED system, outlining specific categories and credits, which prime the students on what to expect in their coming data-gathering tasks. These topics are all covered by the instructors. The spring course starts with reviewing the LEED Rating system as a primer, using the system as a baseline for understanding the future criteria. The following weeks of the spring course are dedicated to the two systems used in the class: the WELL Building Standard and the Living Building Challenge (LBC). These topics are covered first by the instructor, and then by guest speakers from the organizations themselves to provide additional insight and perspective. The first unit is synthesized in both courses in the last week of Unit 1 through teamwork exercises as shown in Table 2.

The remainder of the semester is divided into two for both courses. The students in the fall course are challenged with exploring and documenting every credit in the LEED Operations and Maintenance system, which is a significant number. To facilitate this, the students are put into six groups, which will be described later, and given a selection of complementary or categorized credits. Because there are so many credits in the LEED system, the total number of credits are split into two, creating a Unit 2 and Unit 3 in the course structure as illustrated in Table 2. For Unit 2, the six groups explore and document a series of credits, then present their findings to the class. The groups then have a second round of credits for Unit 3, which they explore in detail and again present to the class. Throughout Unit 2 and 3, different topics from the LEED rating system are being addressed as a class, with guest speakers from the building's operations team to provide real-world insight.
For the spring course, the students are also put into interdisciplinary groups. For Unit 2, these groups are tasked with presenting in-depth coverage of different WELL/ LBC categories and credits, ensuring that the entire class as a basic knowledge about the thresholds and intents for each. For Unit 3, these teams are paired with local design firms who have projects underway. The student teams are tasked with assessing the partners' designs from the perspectives of the two rating systems, WELL and LBC, and providing an initial assessment of how the projects would measure up were the partners and clients interested in pursuing either certification or specific strategies.

\section{INTERDISCIPLINARY STUDENT POPULATIONS}

The goal of both courses is to explore these topics through an interdisciplinary lens. Architecture students are the majority in both courses, though the populations moves toward reaching an equilibrium over the years. The fall course engages more civil engineering students, even though they are also interested in the spring course. The Civil Engineering Department does not currently allow the spring course to count credit toward their degrees, resulting in a lower population of engineers in the later years of the spring course as shown in figure 1 . The fall course consists largely of architects and engineers, with a small group of environmental sciences students, which often have a focused interest in some aspect of the built environment: renewable energy, stormwater, material composition, etc. For the first four years, the fall LEED Lab course was capped at thirty students and regularly settled out in the twenties. This fall class was marketed heavily in the first year to engineering and environmental sciences programs, as well as through student and sustainability listserves across campus. No further marketing has been done since Year 1. 

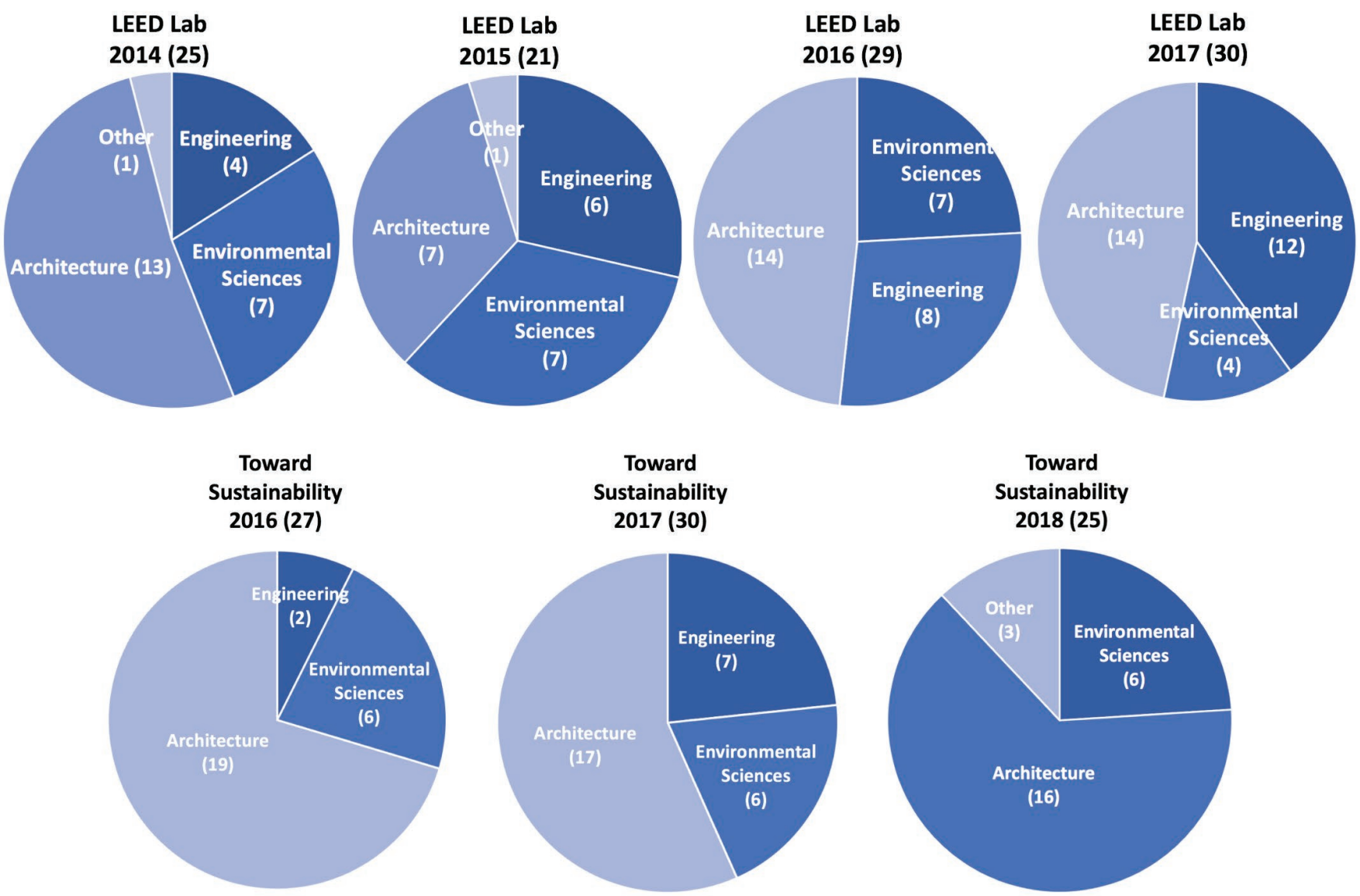

Figure 1. Population diversity across courses and years.

The same registration structure was put in place for the spring Toward Sustainability course focusing on health, capping the class at thirty. This course, unlike the fall building operations course, was more diverse in topic and notably architecture heavy. This can likely be credited to familiarity of the instructor, as well as word-of-mouth around the College from students that have previously taken the course. No targeted marketing was done like that which was done for the fall course. Figure 1 shows the difference in student populations over the four years the courses have been offered. The fall LEED Lab course has increased in popularity with engineers and remained steady with architects. The spring Toward Sustainability course is slowly gaining popularity in other disciplines such as public health, but lost students from engineering.

Because both courses emphasize interdisciplinarity as one of the key elements, substantial time is committed to team building. Not only will this benefit the students as they work in interdisciplinary groups throughout the semester, this will hopefully carry through to professional practice, supporting better communications and collaborations on project teams.
Team building exercises are an integral part of setting the tone for an interdisciplinary course. The goal of these exercises is to establish a level of comfort, or, more appropriately, foundationally establish a level of communication at the personal level rather than the discipline level, building on the notion that teams that have experienced higher levels of bonding are more inclined to share personal knowledge (Han and Hovav 2013). In other words, instead of identifying their teammates as "the engineer" or "the architect," the connections can become relevant at individual levels.

This connection is primarily supported through two exercises: Myths and Stereotypes, and The Most Interesting Person in the Room (Rider and Bowen 2016). The first exercise focuses on flushing out sometimes damaging preconceived notions that different disciplines may have about each other, which can subconsciously impede team work. In this exercise, the students in the class are divided into their disciplinary groups and given the task to provide three stereotypes about each of the disciplines, including their own. By vocalizing the strange myths and stereotypes 
about themselves, such as "always wears black" (architects) and "loves World of Warcraft" (engineers), the students from all disciplines are able to see the silliness and even absurdity of many assumptions that are cultivated between collaborating fields.

The second exercise, The Most Interesting Person in the Room, focuses on a connection to individuals. The students are paired up with a classmate that they do not already know, and the pair is given one minute for Person $A$ to interview Person $B$, then another minute for Person $B$ to interview Person $A$. With the note that this exercise is not a competition, the goal is to find out what makes the person unique or interesting. Once the two "interviews" are completed, each person is given thirty seconds to introduce their partner to the class, positioning them as "the more interesting person in the room." While there are rarely truly extraordinary things that come to light, the interests and background shared are meaningful. Often hobbies, travel, and pets that are revealed from this quick introduction, allowing dog people, for example, to share additional stories later, or those interested in cooking Indian food can search each other out to share recipes. This exercise emphasizes the "power of the personal," providing the opportunity for questions that can elicit experiences and stories to strengthen human connection (Thomas, Kaiser et al. 2017). These exercises toward the beginning of both semesters help to foster collaboration as the teams tackle their projects.

\section{REAL-WORLD COLLABORATIONS}

Throughout the semester, experts from different fields share their expertise with the classes, layering detailed information over the foundational knowledge provided at the beginning of the semester. Expert guest speakers from practice are brought in throughout the two courses to both share expertise across the disciplines as well as to connect the topics addressed in class with the real world. As noted by Mooney (1998), "A well done guest speaker lecture can bring the student into the further liking of the field talked about, and can lead to a full enrollment into it, as well as secondary 'consequences' such as field-related connections, a different point of view on ideas previously taught in a different way, and above all, better learning." For example, the LEED Lab course focuses on building operations and maintenance, and brings in University facility staff in charge of dealing with these issues in the project building daily. Grounds management, waste reduction and recycling, indoor environmental management, housekeeping and energy management are some of the on-the-ground staff that share their insights and expertise with the LEED Lab students. Additionally, if possible, the designer of the projects share insights on the design and delivery of the building, and the engineers are invited to review the energy modeling process, comparing it to how the project is currently operating. These guests are one way in which the students receive real-world knowledge to apply to their explorations.
Guest speakers are also an integral part of the spring course, helping the students to understand the intent of the newer and less-familiar rating systems, such as WELL and LBC. In this course, the guest speakers are fewer because the project is framed differently with respect to real-world engagement. The semester starts with guests from the U.S. Green Building Council (USGBC), the International WELL Building Institute (IWBI), and the International Living Futures Institute (ILFI). These leaders join the class remotely, providing an overview on their systems as well as comparisons with other systems that are being discussed. While these are valuable, the more meaningful real-world collaboration comes from the partnerships with local firms. As seen in Table 2, the teams from the spring course are paired with a local practice and visit the office twice, first to get an overview of the selected project, and then to follow up with any questions they have come across during their assessment process. These interactions are engaging for both the students and the practitioners, allowing the teams to ask questions they would not have otherwise. The meaningful engagement with the real world sticks with the students as a formative experience from their education. As noted by one student,

The objective of coordination and collaboration was clear. Working with various college departments provided real-life scenarios of communication across a colorful spectrum of thought - a task that can be daunting when having to agree, compromise, compose, and present a final product on a deadline. However, that process most clearly and directly aligned with how I have operated over the past 16 years of my professional career; communicating with various owners, engineers, consultants, and contractors to reach a final goal that all can take pride in. These courses stressed the importance of clear and concise communication throughout the collaboration process.

\section{STUDENT FEEDBACK}

Both courses are complex, and have matured over the years that they have been hosted. As of this presentation, LEED Lab has been hosted five times, and Toward Sustainability is in its fourth iteration. The LEED Lab course is more fast-paced and challenging, given the amount of content, while Toward Sustainability is more conceptual and directly addresses the design process. Student evaluations frequently addressed the benefits of interdisciplinary work as well as the connection to real-world through projects and guest speakers:

1. The course was very interesting and a good introduction to what I will have to know in my job field. I also liked that there were other students from different majors in the class. I think having the variety of different majors in the class helped us learn from different perspectives. 
2. This was a great course! The interdisciplinary work between the three schools was beneficial and helped us all to grow as students and helped prepare us for working after school. Doing a real project is rewarding and exciting. It provided a great look at LEED in practice as well as theory.

3. I enjoyed working with the firm, I enjoyed learning about the most advanced standards in building industry, it pushed me to engage more sustainable strategies in my design process.

4. This course is cool because it bring people together from different background to really stir up some talk and hopefully action about keeping our world safe and clean as well as our buildings, and the lives we live within both.

Some negative feedback for the LEED Lab course addressed the complexity of the tasks given, the short timeline allowed for research, and the perceived lack of assessment of team members.

\section{DISCUSSION}

Both courses speak to three critically important issues for future practitioners: (1) in-depth exploration of trending topics in the built environment, namely building operations and health; (2) interdisciplinary team work; and (3) engagement with real-world projects, practitioners and clients. As reviewed, by dividing the semester into three sections, there is the opportunity to scaffold the new information to build toward an appropriate understanding of the complex topics. Emphasis is given early to team building, which is a core component of both courses to facilitate a richer learning experience. This interdisciplinary engagement is valued by the students as regularly evidenced in their course evaluations. Similarly, providing a meaningful opportunity to apply developing knowledge to real-world projects is effective and essential. By not only hearing from experts in the field, but also working with practitioners on documentation and potential design scenarios, students are engaging with design decisions, implementation and assessment at deeper level. As one student said, "Pairing up with an actual firm and working with them to learn the WELL/LBC standards was very beneficial to see how these things are actually implemented in real life." While there are challenges regarding the complexity the content, and the speed at which the students are asked to gather, analyze, synthesize, and present information, this course template provides meaningful and important experience for architecture students moving toward a successful career in a transitioning field.

\section{REFERENCES}

Fixson, S. K. "Teaching Innovation through Interdisciplinary Courses and Programmes," in Product Design and Development: An Analysis at 16 US Schools. Hoboken, NJ: Wiley, 2009.

Han, J. and A. Hovav. "To Bridge or to Bond? Diverse Social Connections in an IS Project Team," International Journal of Project Management 31, no. 3 (2013): 378-390

Keeler, M. and P. Vaidya, Fundamentals of Integrated Design for Sustainable Building. Hoboken, NJ: Wiley, 2016.
Mooney, L. A. "Pitching the Profession: Faculty Guest Speakers in the Classroom," Teaching Sociology (1998): 157-165.

Reed, B. The Integrative Design Guide to Green Building: Redefining the Practice of Sustainability. Hoboken, NJ: Wiley, 2011.

Rider, T. R. "Exploring the Integration of Sustainability and Green Building Themes within Formal Architectural Education," Ph.D. diss., North Carolina State University (2010).

Rider, T. R. and E. Bowen, "Embracing Non-Traditional Partnerships in Design Education: Breaking Down Myths and Stereotypes," in Collaboration and Student Engagement in Design Education, ed., R. Tucker. Hershey, PA: IGI Global, 2016, 283-303.

Smit, E. and M. Tremethick. "Development of an International Interdisciplinary Course: a Strategy to Promote Cultural Competence and Collaboration," Nurse Education in Practice 13, no. 2 (2013): 132-136.

Thomas, G. R., B. L. Kaiser and K. Svabek, "The Power of The Personal: Breaking Down Stereotypes and Building Human Connections," Narrative Inquiry in Bioethics 7, no. 1 (2017): 27-30.

Yudelson, J. Green Building Through Integrated Design. New York: McGraw-Hill Education, 2008. 